\title{
DISCRETE \\ MATHEMATICS FOR COMPUTING
}




\section{DISCRETE \\ MATHEMATICS \\ FOR COMPUTING}

\section{Peter Grossman}

Department of Mathematics

Monash University, Australia

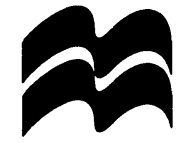




\section{(C) Peter Grossman 1995}

All rights reserved. No reproduction, copy or transmission of this publication may be made without written permission.

No paragraph of this publication may be reproduced, copied or transmitted save with written permission or in accordance with the provisions of the Copyright, Designs and Patents Act 1988, or under the terms of any licence permitting limited copying issued by the Coyright Licensing Agency, 90 Tottenham Court Road, London W1P 9HE.

Any person who does any unauthorised act in relation to this publication may be liable to criminal prosecution and civil claims for damages.

First published 1995 by

\section{MACMILLAN PRESS LTD}

Houndmills, Basingstoke, Hampshire RG21 2XS

and London

Companies and representatives

throughout the world

A catalogue record of this book is available from the British Library.

$\begin{array}{llllllllll}10 & 9 & 8 & 7 & 6 & 5 & 4 & 3 & 2 & 1\end{array}$

$\begin{array}{llllllllll}04 & 03 & 02 & 01 & 00 & 99 & 98 & 97 & 96 & 95\end{array}$ 


\section{Contents}

List of symbols

viii

Preface

1 Introduction to Algorithms

1.1 What is an algorithm?

1.2 Control structures

1.3 Further examples of algorithms

Exercises

2 Bases and Number Representation

2.1 Real numbers and the decimal number system 14

$\begin{array}{lll}2.2 & \text { The binary number system } & 15\end{array}$

$\begin{array}{lll}2.3 & \text { Conversion from decimal to binary } & 17\end{array}$

$\begin{array}{lll}2.4 & \text { The octal and hexadecimal systems } & 21\end{array}$

2.5 Arithmetic in non-decimal bases 24

$\begin{array}{ll}\text { Exercises } & 26\end{array}$

3 Computer Representation and Arithmetic

3.1 Representing numbers in a computer 28

3.2 Representing integers 28

3.3 Arithmetic with integers 31

3.4 Representing real numbers 34

3.5 Arithmetic with real numbers 38

3.6 Binary coded decimal representation 40

Exercises $\quad 41$

4 LogIC

4.1 Logic and computing 44

4.2 Propositions 44

4.3 Connectives and truth tables 46

4.4 Compound propositions 49

4.5 Logical equivalence $\quad 52$

4.6 Laws of logic 54

4.7 Predicate logic $\quad 59$

Exercises $\quad 65$ 
vi CONTENTS

5 Sets and Relations

$\begin{array}{lll}5.1 & \text { Sets } & 69\end{array}$

5.2 Subsets, set operations and Venn diagrams $\quad 71$

$\begin{array}{lll}5.3 & \text { Cardinality and Cartesian products } & 77\end{array}$

5.4 Computer representation of sets 80

$\begin{array}{lll}5.5 & \text { Relations } & 82\end{array}$

Exercises $\quad 89$

6 Functions

6.1 Functions and computing 92

6.2 Composite functions and the inverse of a function 98

6.3 Functions in programming languages 104

$\begin{array}{ll}\text { Exercises } & 106\end{array}$

7 INDUCTION AND RECURSION

$\begin{array}{lll}7.1 & \text { Recursion and sequences } & 109\end{array}$

$\begin{array}{lll}7.2 & \text { Proof by induction } & 115\end{array}$

$\begin{array}{lll}7.3 & \text { Induction and recursion } & 119\end{array}$

$\begin{array}{lll}7.4 & \text { Recursively defined functions and recursive algorithms } & 121\end{array}$

7.5 Recursively defined functions in programming languages 126

$\begin{array}{ll}\text { Exercises } & 128\end{array}$

8 Boolean Algebra and Digital Circuits

$\begin{array}{lll}8.1 & \text { Boolean algebra } & 133\end{array}$

8.2 Simplifying Boolean expressions 138

$\begin{array}{lll}\text { 8.3 Digital circuits } & 140\end{array}$

8.4 Disjunctive normal form and Karnaugh maps 146

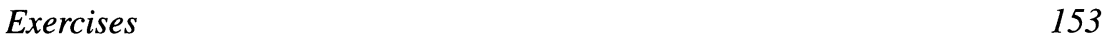

9 Combinatorics

9.1 Combinatorics and computing 158

$\begin{array}{lll}9.2 & \text { The Multiplication principle } & 158\end{array}$

$\begin{array}{lll}9.3 & \text { Permutations } & 161\end{array}$

$\begin{array}{lll}9.4 & \text { Combinations } & 163\end{array}$

$\begin{array}{ll}\text { Exercises } & 167\end{array}$

10 Introduction to Graph Theory

$\begin{array}{ll}10.1 \text { What is a graph? } & 170\end{array}$

$\begin{array}{ll}10.2 \text { Basic concepts in graph theory } & 170\end{array}$

$\begin{array}{ll}10.3 \text { The matrix representation of a graph } & 177\end{array}$

$\begin{array}{ll}10.4 \text { Isomorphism of graphs } & 179\end{array}$

10.5 Paths and circuits 182

Exercises 192 
11 Trees

11.1 Introduction to trees

11.2 Local area networks and minimal spanning trees 199

$\begin{array}{ll}11.3 \text { Minimal distance paths } & 205\end{array}$

$\begin{array}{ll}11.4 \text { Rooted trees } & 207\end{array}$

$\begin{array}{ll}\text { Exercises } & 212\end{array}$

12 Number Theory

$\begin{array}{ll}12.1 \text { What is number theory? } & 215\end{array}$

$\begin{array}{ll}12.2 \text { Divisibility and prime numbers } & 215\end{array}$

12.3 Greatest common divisors and the Euclidean algorithm 218

$\begin{array}{ll}12.4 \text { Congruences } & 223\end{array}$

$\begin{array}{ll}12.5 & \text { Pseudo-random number generation } \\ 12.6 & 230\end{array}$

12.6 Proof of the Fundamental theorem of arithmetic 234

$\begin{array}{ll}\text { Exercises } & 234\end{array}$

13 Algorithms and Computational Complexity

13.1 How long does an algorithm take to run? 237

13.2 Dominant operations and the first two approximations 238

13.3 Comparing functions and the third approximation 240

13.4 The fourth approximation and the $\mathrm{O}(f)$ notation 246

$\begin{array}{ll}13.5 \text { Sorting algorithms } & 249\end{array}$

13.6 Tractable and intractable algorithms 254

$\begin{array}{ll}\text { Exercises } & 258\end{array}$

$\begin{array}{ll}\text { Answers to exercises } & 260\end{array}$

$\begin{array}{ll}\text { Index } & 284\end{array}$ 


\section{List OF Symbols}

Logic

$p \wedge q$

$p \vee q$

$\neg p$

$p \rightarrow q$

$p \leftrightarrow q$

$p \oplus q$

$p \mid q$

$P \equiv Q$

$\forall$

$\exists$

$p$ and $q$

4.3

$p$ or $q$

4.3

not $p$

4.3

if $p$ then $q$

4.3

$p$ if and only if $q$

4.3

$p$ xor $q$ (i.e. $p$ or $q$ but not both)

4: Exercise 3

$p$ nand $q$ (i.e. not both $p$ and $q$ )

4: Exercise 17

$P$ is logically equivalent to $Q$

4.5 and 4.6

for all

4.7

there exists

4.7

\section{Sets}

$\{\ldots\}$

:

$x \in A$

$x \notin A$

$\varnothing$

$\mathscr{E}$

$\mathbf{N}$

J

Q

$\mathbf{R}$

$A \subseteq B$

$A \cap B$

$A \cup B$

$\bar{A}$

$A-B$

$|A|$

$\mathscr{P}(A)$

$A \times B$

$A^{n}$

$\left(x_{1}, \ldots, x_{n}\right)$

$E(x)$

'the set of ...'

such that

$x$ is an element of $A$

$x$ is not an element of $A$

null set

universal set

the set of natural numbers

the set of integers

the set of rational numbers

the set of real numbers

$A$ is a subset of $B$

intersection of $A$ and $B$

union of $A$ and $B$

complement of $A$

(set) difference of $A$ and $B$

cardinality of $A$

power set of $A$

Cartesian product of $A$ and $B$

$n$-fold Cartesian product of

$A$ with itself

ordered $n$-tuple

equivalence class containing $x$ 


\section{Functions}

$f: A \rightarrow B$

$f$ is a function with domain $A$ and codomain $B$

6.1

$f(x)$

image of $x$ under $f$

6.1

$g \circ f$

composite function of $f$ and $g$

6.2

identity function (on a set)

6.2

$f^{-1}$

inverse of $f$

6.2

\section{Boolean algebra}

$x+y$

$x \times y$

$x^{\prime}$

0

1
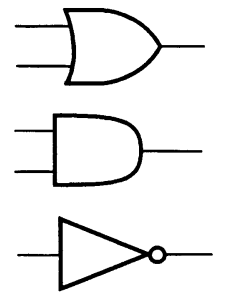

Boolean sum of $x$ and $y$

8.1

Boolean product of $x$ and $y$

Boolean complement of $x$

Boolean zero

Boolean one

OR gate

inverter (or NOT gate)

8.1

8.1

8.1

8.1

8.3

8.3
AND gate

9.3

$n$ factorial

number of permutations of $n$ objects chosen from a set of $r$ objects

9.3

${ }^{n} C_{r},\left(\begin{array}{l}n \\ r\end{array}\right)$

number of combinations of $n$ objects chosen from a set of $r$ objects

10.2

10.2

11.3

11.2 and 11.3

Number theory

$a \mid b$

$a \nmid b$

$\operatorname{gcd}(a, b)$

$\operatorname{lcm}(a, b)$

$a \equiv b \bmod m$ $a$ divides $b$

$a$ does not divide $b$

12.2

greatest common divisor of $a$ and $b \quad 12.3$

least common multiple of $a$ and $b \quad 12.3$

$a$ is congruent to $b$ modulo $m$ 
$\boldsymbol{x}$ List of Symbols

Other symbols

$\{\ldots\}$

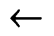

$a \operatorname{div} b$

$a \bmod b$

$\left\lfloor n_{\rfloor}\right.$

$\operatorname{frac}(n)$

$\sum_{i=m}^{n}$

$\mathrm{O}(f)$

$\lg n$ comment (in an algorithm)

'is assigned the value of'

(in an algorithm)

integer quotient of $a$ and $b$

remainder after $a$ is divided by $b$

integer part of $n$

fractional part of $n$

sum with $i$ varying from $m$ to $n$

'big $\mathrm{O}$ ' of $f$

logarithm to the base 2 of $n$
1.1

1.1

2.3

2.3

2.3

2.3

7.2 and 7: Exercise 13

13.4

13.5 


\section{Preface}

This book is an introductory text on a number of topics in discrete mathematics, intended primarily for students undertaking a first degree in computing. The book has grown out of a set of my lecture notes used for the past two years in the first-year one-semester subject Discrete Mathematics at the Caulfield and Peninsula campuses of Monash University. The subject is available to students who are undertaking the Bachelor of Computing degree with a major in computer technology, information systems, software development, or computer application development.

Over the past 15 years or so, there has been an enormous expansion in the number and variety of degree courses being offered in computing and computer-related areas. Over a similar period, the term 'discrete mathematics' has been used widely to describe the collection of topics that form the prerequisite mathematical knowledge for studies in computing. Many textbooks are available with the words 'discrete mathematics' and either 'computing' or 'computer science' in their titles. These books generally cover the same broad range of topics: symbolic logic, sets, functions, induction, recursion, Boolean algebra, combinatorics, graph theory, and number theory, and also in some cases probability theory, abstract algebra, and mathematical models of computation. The unifying themes in these otherwise rather disparate topics are an emphasis on finite or countably infinite (hence 'discrete') mathematical structures, the use of an algorithmic approach to solving problems, and the applicability of the topics to problems arising in the study of computers and computing.

Academic authors often justify writing a new textbook by claiming that there was no book on the market that met the needs of their course. This is indeed the case here, but some further explanation is in order. There are many excellent discrete mathematics textbooks addressed principally to students of computer science. The reader of these books is typically assumed to have obtained at least a solid grounding in mathematics at final-year school level, the mathematics is often presented in a rather abstract style, and many of the examples used to illustrate the theory are drawn from computer science.

The students entering the Bachelor of Computing degree at Monash, however, come from a wider range of mathematical backgrounds. Some have substantial mathematical studies behind them, but there are others who have studied only a little mathematics in their final two years of school, in some cases many years before they began their tertiary studies. Furthermore, the 
course has a strong emphasis on information systems and commercial computing, and so the more abstract topics in theoretical computer science hold little interest for these students.

My aim, therefore, in writing this book, has been to cover the topics in discrete mathematics that I believe are appropriate for a course of this nature, and to present them in a way that makes them accessible to students with a modest mathematical background. A knowledge of calculus is not required, and even the level of facility assumed in algebra is fairly basic. A student who has seen sets and functions before will be at an advantage, but these topics are not prerequisite knowledge. A knowledge of programming is not required either, although a student who has done some programming will be able to relate that work to the material on algorithms in this book.

A brief summary of the contents of the book follows. Algorithms are discussed in Chapter 1, and a pseudocode notation is established, which is then used frequently in the subsequent chapters. Chapter 2 deals with non-decimal number systems, and in Chapter 3 the representation of integers and real numbers in a computer is explained. This is perhaps an unusual topic to find in a discrete mathematics textbook, but it provides an opportunity for students to relate mathematics to their work in other subjects. Chapter 4 is an introduction to propositional and predicate logic. Chapter 5 deals with sets and relations, and Chapter 6 with functions. Given the difficulty that many students have with grasping abstract mathematical concepts, the treatment of these topics in particular is gradual and informal. In Chapter 6, the emphasis is on thinking of functions as processes with input and output; the 'ordered pair' definition of a function is not mentioned. An unusual feature in Chapter 6 is a discussion of the relationship between the mathematical and programming concepts of a function. Chapter 7 deals with recursive algorithms and proof by induction, and includes a brief section on recursion in programming languages. Chapter 8 begins with a careful introduction to Boolean algebra, in which it is made clear that this topic is not just propositional logic in another notation but a branch of mathematics that can be used to unify the study of logic, sets, and other structures. The sections on digital circuit design and Karnaugh maps may seem out of place in a textbook that claims to have an emphasis on information systems, but these topics provide a realistic example of an area in which Boolean algebra is used, and for this reason I believe that a worthwhile purpose is served by including them. Chapter 9 deals with basic combinatorics. Graph theory is introduced in Chapter 10, and this leads into the study of trees and their applications in Chapter 11. Chapter 12 is an introduction to number theory, and includes a section on the application of modular arithmetic to the generation of pseudo-random numbers. Finally, Chapter 13 provides an introduction to the concepts of the time complexity and tractability of algorithms.

The exercises at the end of each chapter include questions that provide practice in routine computational techniques, as well as some more challenging problems designed to develop a deeper level of understanding of the material. Answers to all exercises for which a short answer can sensibly be given are provided at the end of the book. 
My aim throughout the book has been to present the material in a fairly informal style, without sacrificing mathematical correctness. I am aware of the danger that, in aiming for informality, one can easily write mathematical statements that do not stand up to scrutiny when analysed carefully. It would be very easy, for example, to inadvertently define a cycle in a graph in a way that admits a single vertex as a cycle, which of course would then make nonsense of the definition of a tree as a connected graph with no cycles. The definitions in this book may not always be expressed with the level of mathematical formality to which professional mathematicians are accustomed, but they do mean what they say!

I would like to express my gratitude to a number of people whose assistance has been indispensable in the preparation of this book. First, I wish to thank my colleagues at Monash University: Cristina Varsavsky and Pam Norton from the Department of Mathematics, Ian Kirkwood from the Syme Division of Econometrics, and Chris Avram from the Department of Computer Technology, whose criticisms of a draft version of the manuscript were invaluable to me when I was putting the text into its final form. I am very grateful to the students taking the subject Discrete Mathematics who made suggestions for improving the book and pointed out some errors. The comments made by the anonymous reviewers appointed by Macmillan were also helpful, and were greatly appreciated. The artwork for the diagrams was very capably produced by Liz Butler and Jean Sheldon, to whom I express my sincere thanks. My thanks go to Marjorie Pressley for her careful and thorough editing. I acknowledge the support of the Department of Mathematics at Monash University in providing me with the time and facilities I needed while I was writing the book. Finally, I would like to thank Peter Debus, Elizabeth Gibson, and the staff at Macmillan Education Australia for their assistance during the production of this book. 